\title{
Bismuth-Catalyzed Synthesis of Macrocyle Bisguanidines
}

\section{Amenson Gomes* and Silvio Cunha}

Universidade Federal da Bahia, Instituto de Química, Campus de Ondina, 40170-290, Salvador-BA. INCT-Instituto Nacional de Ciência e Tecnologia em Energia e Ambiente, Campus de Ondina, Salvador-BA *amenson@gmail.com

Keywords:bisguanidine, bisthiurea, bismuth

\section{INTRODUCTION}

The bisguanidines are a class of substances characterized by the presence of two guanidine groups separated by a carbon chain, Figure 1. The strong basicity of bisguanidines is due to stabilization of its conjugate acid by resonance effect, which occurs in each of the guanidine groups $^{1}$. The bisguanidines have a broad pharmacological potential, with antiseptic, antihypertensive, anti-inflammatory, antitrypanosomiasis, antidepressant, antitumor and antiviral activities. ${ }^{2}$ The presence of nitrogen atoms and the planar geometry of guanidinium group allows for bisguanidines act as ligand for different metals, an important feature for the bioinorganic chemistry, ${ }^{3}$ as well as for organocatalises. ${ }^{4}$ Due to large spectrum of activity of the bisguanidines, we developed a synthetic route to synthesize macrocycle bisguanidines through the reaction of bisthiourea and amines, promoted by a mixture of $\mathrm{NaBIO}_{3} / \mathrm{Bil}_{3}$.

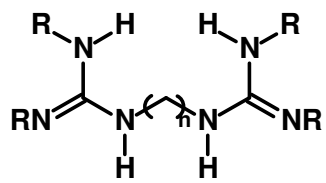

Figura 1. Bisguanidine general structure

\section{RESULTS AND DISCUSSION}

To access the gisguanidines, we used the $\mathrm{NaBlO}_{3}$ as oxidant agent and the $\mathrm{Bil}_{3} 5 \mathrm{~mol} \%$ as thiophile in the guanilation reaction. The reaction was performed in acetonitrile as solvent during 24 hours and reflux, Scheme 1. The $\mathrm{Bi}(\mathrm{III})$ should behave as thiophilic soft Lewis acid that coordinated to the thiourea followed by reaction with diamine and desulfurization after the $\mathrm{Et}_{3} \mathrm{~N}$ to attack. It was seen that in the reaction of bisthiourea with $n_{1}=2$ and diamine, there was an intramolecular reaction producing the compound shown in Figure 2.<smiles>S=C(Nc1ccccc1)N1CCNC1=Nc1ccccc1</smiles>

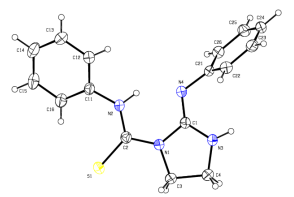

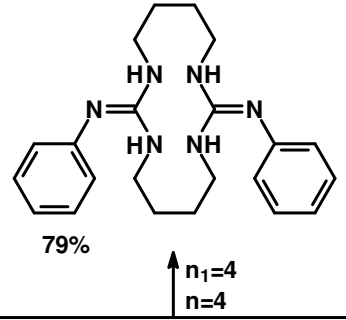
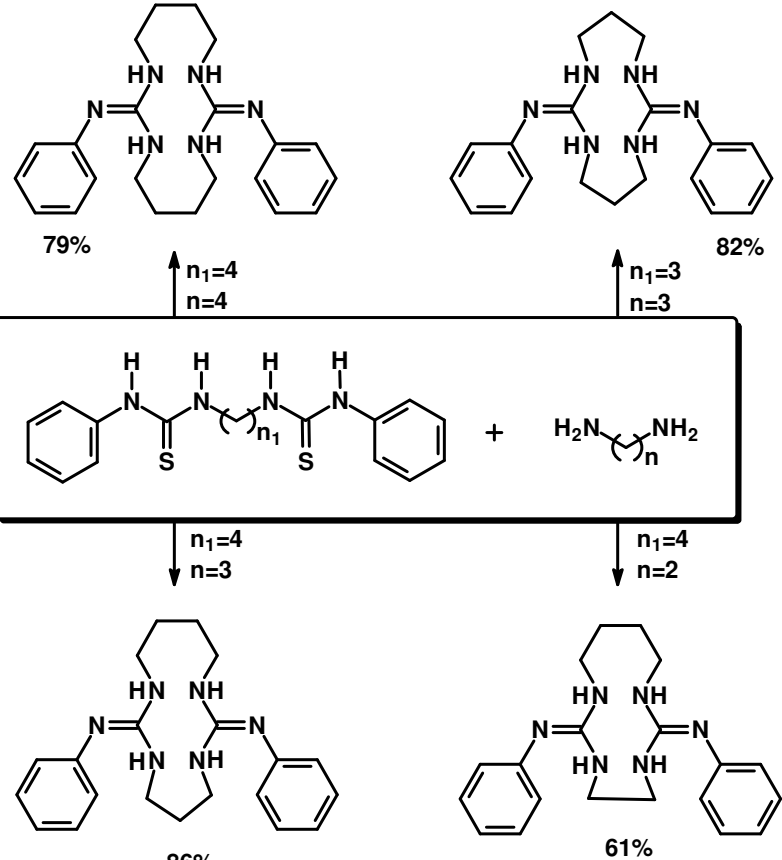

$86 \%$

$61 \%$

Reactions Condintions: $\mathrm{NaBiO}_{3}, \mathrm{Bil}_{3}(5 \mathrm{~mol} \%), \mathrm{Et}_{3} \mathrm{~N}, \mathrm{CH}_{3} \mathrm{CN}$, reflux.

Scheme 1. Macrocyclic Bisguanidines

\section{CONCLUSION}

This methodology showed to be effective in the synthesis of macrocyclic bisguanidines with good yields, giving an alternative to synthesis of this class of compound.

\section{ACKNOWLEDGEMENTS}

\section{UFBA CNPQ CAPES}

\section{REFERENCES}

${ }^{1}$ Wang, Y; Sauer, D. R.; Djuric, S. W. Tetrahedron Lett. 2009, 50, 5149.

${ }^{2}$ Greenhill, J. V.; Lee, L. In Ellis, G. P.; Luscombe, D. K., Eds.; Progress in Medicinal Chemistry; Elsevier Science: New York 1993; Vol. 30; Chaper 5.

${ }^{3}$ Herres-Pawlis, S.; Ulrich, F.; Henkel, G. Acta Cryst. 2006, E62, 2138.

${ }^{4}$ Tanaka, Shinji; Nagasawa, K. Synlett 2009, 4, 667.

Figure 2. Product of the intramolecular reaction 